\title{
New sanitation techniques for controlling Tephritid Fruit Flies (Diptera: Tephritidae) in Hawaii
}

\section{KLUNGNESS, L M ${ }^{1}$; ERIC B. JANG ${ }^{1}$; RONALD F. L. MAU'² ROGER I. VARGAS ${ }^{1}$; JARI S. SUGANO ${ }^{2}$; EARL FUJITANI ${ }^{3}$.}

\author{
${ }^{1}$ Pacific Basin Agricultural Research Center, USDA, Agricultural Research Service, P. O. Box 4459, Hilo, Hawaii, 96720, USA \\ ${ }^{2}$ Department of Plant and Environmental Protection Sciences, 310 Gilmore Hall, University of Hawaii, 3050 Maile Way, Honolulu, Hawaii, \\ 96822, USA \\ ${ }^{3}$ Maui Agricultural Research Center, University of Hawaii, P. O. Box 269, Kula, Hawaii, 96729, USA
}

\begin{abstract}
New approaches to sanitation in a cropping system susceptible to tephritid fruit flies (Diptera tephritidae) in Hawaii have been investigated. Six trials were conducted in tent-like structures to demonstrate that melon fly larvae (Bacrocera cucurbitae, Coquillett) are not reliably controlled by malathion sprayed on the surface of whole or smashed fruit. Smashing fruit does not sufficiently reduce the rate of eclosion to be a reliable population control measure. Tilling fruit into the ground only partially reduced eclosion. Burying fruit 0.15 and $0.30 \mathrm{~m}$ deep also partially reduced eclosion. Burying fruit $0.46 \mathrm{~m}$ deep prevented adult fly eclosion. Screen between the infested fruit and the ground prevented $90.2 \%$ of fly eclosion (edges of the screen were buried to prevent the escape of eclosing adult flies). Larvae pupate within $0.7 \mathrm{~m}$ from their host fruit (mean distance $=13.88 \pm 1.76 \mathrm{~cm}, 95 \% \mathrm{Cl}=$ 10.4 to $17.4 \mathrm{~cm}$ ). Augmentoria entrapped all adult flies eclosing from fruit placed inside the structure. The data suggests that the three (3) methods of interdicting adult fly eclosion should be practiced. They are, in order of effectiveness, placing cull fruit in augmentoria, burying the fruit $0.46 \mathrm{~m}$ under ground, or placing fruit on screen under and 0.7 m beyond the fruit pile.@ JASEM
\end{abstract}

Although extensive efforts to apply many technologies to the control of fruit flies have been tried all over the world (Keng-Hong Tan, 2000), one part of the fruit fly life cycle has been overlooked in many of these control programs. Specifically, we are referring to the stages post-oviposition to adulteclosion. In eradication programs such as those practiced by the California Department of Food and Agriculture, the need to remove infested fruit from the environment was recognized, and fruit stripping and disposal is part of the regular strategy when the presence of an infestation of a quarantine fruit fly is detected (Dowell et. al., 2000). The Secretariat of the Pacific encourages fruit sanitation in their Project on Regional Management of Fruit Flies in the Pacific by threatening to remove the export registration of offending growers (Allwood, 2000). Taiwan's national fruit fly control program also encourages field sanitation as an essential part of their Oriental fruit fly control program (according to the director of the Dept. of Plant Protection, Ching-Wen Kao, pers. commun.). In Surinam, papayas are exported from the country under a quarantine system that mandates field sanitation (van Sauers-Muller, 1993). The Oriental fruit fly (Bactrocera dorsalis (Hendel)) eradication program in Mauritius included a fruit sanitation component (Seewooruthun et. al., 2000). With the aforementioned exceptions, in countries where fruit flies are well established, very little organized effort has been made to encourage the removal of infested fruit from the cropping system. Where farmers are careful to till their crops after final harvest, the fruit fly may be reduced, but not all larvae are killed by the cultivation (Klungness, 2001, Pandey, 2004). Although the actual mortality of larvae inside the fruit after pesticide application was very seldom carefully checked or reported in the literature, it was probably not high. No systemic pesticide is licensed for use on edible vegetable crops at time of fruiting in Hawaii. Field observations indicate that tephritid larvae often pupate under the fruit from which they emerge, thereby avoiding contact with a surface application of pesticide.

Because of the recent efforts of the Environmental Protection Agency to reduce the use of organophosphate pesticides in agricultural crops, integrated pest management (IPM) has become the preferred strategy for pest control. To control tephritid fruit flies in Hawaii, an Integrated Pest Management program (HAW_FLYPM) has been undertaken with funding from the United States Department of Agriculture, Agriculture Research Service, Area-wide Program. As part of that program, we have evaluated the following null hypotheses about fruit flies: (1) Pesticides have not effect on fruit fly larvae within fruit or soil. (2) sanitation techniques (burying, tenting, smashing or chopping, placing screen under cull fruit) do not impact survival of larvae to adult flies.

\section{MATERIALS AND METHODS}

Augmentorium (plural: augmentoria) is defined as a tent-like structure designed to sequester tephritid flies 
emerging from infested fruit, but which allows the escape of parasitoid wasps. The augmentorium is constructed from a material with a weave tight enough to prohibit fruit fly larvae from passing through the material [translucent Lumite ${ }^{\circledR}, 55$ x 55 mesh (Synthetic Industries, Gainsville Georgia)]. The upper roof of the augmentorium (at least $1 \mathrm{~m}$ above ground) is made with a material [Phifertex ${ }^{\circledR}$ (Phifer Wire Products, Inc., Tuscaloosa, Alabama)] that has openings large enough to permit the egress of adult parasitoids (13 by 12 mesh or 1 by $1.3 \mathrm{~mm}$ openings), but has been shown to be highly effective in preventing the egress of the adult tephritid fruit fly of all four species present in Hawaii. The augmentorium has a skirt of material that is buried in the ground to prevent tephritid larvae from escaping the enclosure under ground. Infested fruit is placed in the augmentorium through a circular sock of same material used in the tent walls. This prevents adult flies from escaping during the loading process, after which the sock is rolled tightly and clamped (Fig.1A and $\mathrm{B}$ ). When available, augmentoria were used in various comparison trials to evaluate the effectiveness of various sanitation techniques. Among these treatments were pesticide, ground screen, chopping fruit, tilling and burying fruit. All trials were conducted in the Kula area on the island of Maui, Hawaii.
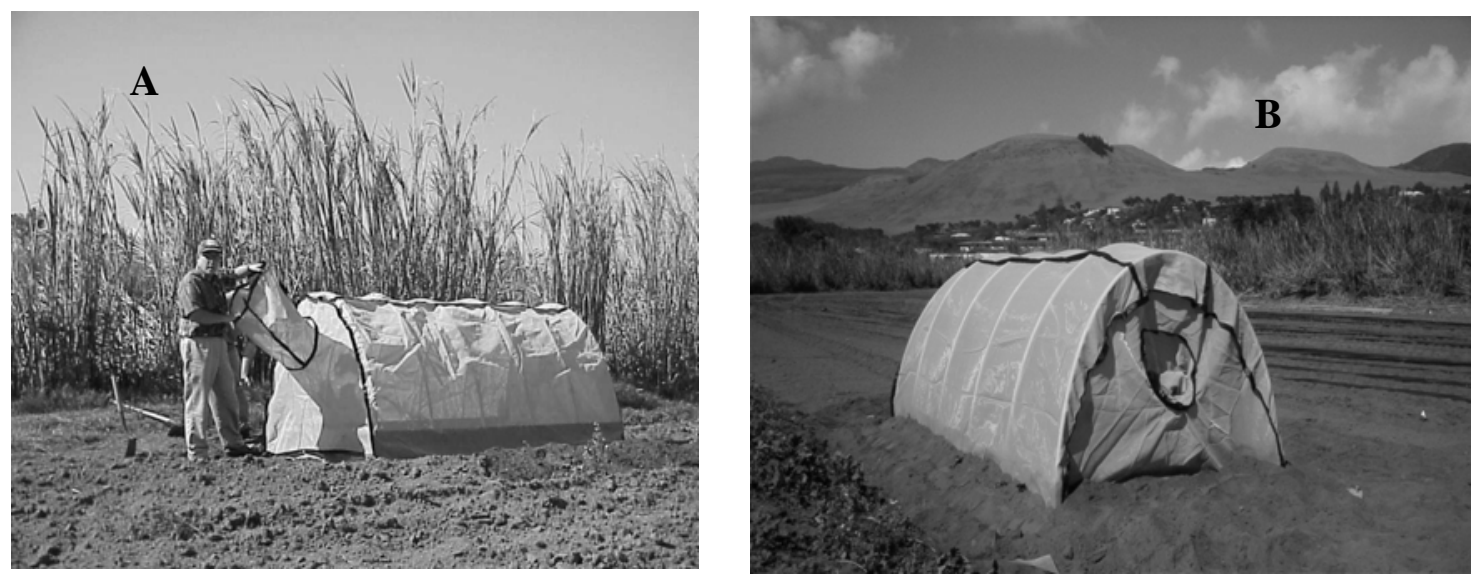

Fig. 1. Augmentorium: a) Eric Jang holding loading shoot of augmentorium being installed, b) fully installed.

Trial 1: Four augmentoria were available at the Maui Agricultural Research Center to evaluate the following treatments of infested fruit: (1) control (infested fruit placed in augmentorium), (2) ground screen [Phifertex ${ }^{\circledR}, 13$ by 12 mesh (Phifer Wire Products, Inc., Tuscaloosa, Alabama) was placed on the ground area of the augmentorium and the edges buried with the skirt of the augmentorium], (3) smashed fruit [infested fruit placed in augmentorium, after the culled fruit was smashed using a soil compacter (designed and built at the Maui Agriculture Research Station, Fig. 2)], (4) smashed fruit with surface pesticide [infested fruit treated once with malathion at $0.287 \mathrm{l} / \mathrm{ha}(1.858 \mathrm{ml} / \mathrm{l})]$. The Phifertex ${ }^{\circledR}$ screen in treatment 2 left the larvae with no choice but to penetrate the screen and pupate under or on top of it. Melon fly infested zucchini (Cucurbitae pepo L.) was collect from 2 farms in Kula on 12 Dec. 2001 and randomly divided into approximately 4 equal portions. Mass $(\mathrm{kg})$ and number of fruit by treatment were: (1) 36 and 118, (2) 36 and 135, (3) 33 and 122, (4) 35 and 124. Each bucket of fruit was introduced into one of the augmentoria for treatment. Solulys AST protein bait
(Roquette America, Bridgeview, Illinois) was mixed at $8 \%$ with borax $(4 \%)$ in tap water. Bait $(300 \mathrm{ml})$ was placed in 8 yellow bottom dome traps (Great Lakes IPM, Inc., Vestaburg, Michigan). Two traps were hung from the roof inside each augmentorium, and these were monitored every week for the duration of adult fly emergence.

Trial 2: This trial on 3/11/01 was also conducted at the Maui Agricultural Research Station. The zucchini was collected at another commercial farm. Mass $(\mathrm{kg})$ and number of fruit per treatment were (1) 38 and 146, (2) 39 and 129, (3) 39 and 145, (4) 41 and 137. Trial 3: This trial on 5/22/01 was also a replication of trial 1 , but the augmentoria were moved to the farm of a third commercial grower. The zucchini was again collected at a commercial farm. Mass $(\mathrm{kg})$ and number of fruit per treatment were (1) 33 and 116, (2) 35 and 118, (3) 34 and 117, (4) 35 and 104. In spite of variation in the total emergence between trials 1,2 , and 3 , they were analyzed together to provide replication. We applied analysis of variance using the GLM procedure (SAS, 1988) with and without nesting within date to compare the treatments. 


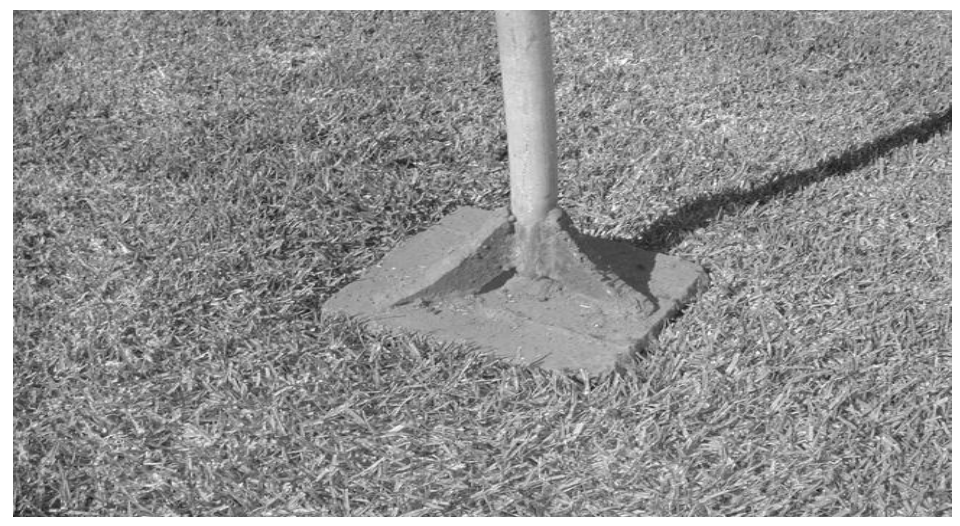

Fig 2. Metal soil compactor used to smash fruit for trials 1 through 4 .

Trial 4: This trial was conducted with the same 4 augmentoria at the same farm on 7/19/01. Zucchini fruit was collected at two nearby farms. The treatments were changed: (1) control (augmentorium with whole fruit), (2) whole fruit with 3 weekly applications of malathion [0.287 1/ha $(1.858 \mathrm{~mL} / \mathrm{L})]$, (3) smashed fruit (smashed as previously described and placed in augmentorium) (4) smashed fruit with malathion applications [as in treatment (2)]. Fruit were divided as previously described. Fruit mass (kg) and numbers per treatment were (1) 37and 113, (2) 38 and 102, (3) 38 and 102, (4) 38 and 104. Total emergence was calculated for each treatment from dome traps sampled weekly. Results were compared by binomial confidence intervals (Wonnacott and Wonnacott, 1977), because it was deemed unnecessary to replicate the trial.

Trial 5: The same 4 large augmentoria were again installed on the Maui Agricultural Research Center property to evaluate the following treatments: (1) Phifertex ${ }^{\circledR}$ screen on ground with edges buried inside the floor area of the augmentoria (2 replicates), (2) window screen on ground with edges buried inside the floor area of the augmentoria (2 replicates). (3) fruit piled on screen ( 1 pile on Phifertex ${ }^{\circledR}$, 1 pile on widow screen), (4) fruit spread out flat on Phifertex ${ }^{\circledR}$ and on window screen in the remaining two augmentoria. Total adult trap-capture was calculated for each treatment from dome traps. Results were compared by binomial confidence intervals because replications were limited by the number of available augmentoria. At the end of the trial, augmentoria screens were removed, and soil bores were taken to ca. $8 \mathrm{~cm}$ depth in the soil at 10 locations around the outside of each screen. Measurements were taken from the nearest fruit to the inside and to the outside edge of the borehole. Distance of the bore from the edge of the screen was also recorded. Number of puparia recovered in the each bore was recorded. The approximate volume of the bore was $603.4 \mathrm{~cm}^{3}$, based on the diameter $(9.8 \mathrm{~cm})$ and the standard depth of penetration $(8 \mathrm{~cm})$. The floor screen was then carefully removed, number of adult flies trapped under the screen recorded, and 3 soil bores taken in the ground under the screen. Numbers of puparia recovered in the bores were recorded. This was repeated for each of the 4 augmentoria. The results of the flies recovered in the traps, and under the screen were both subject to 2-way analysis of variance (GLM, SAS Institute, 1988) with screen and fruit configuration as levels in the analysis. The results of the soil bores were also subjected to 2-way analysis of variance with the screen and fruit configuration as levels in the analysis. The distance of the puparia recovered from the nearest fruit was regressed against numbers recovered.

Trial 6: To determine the effects of burying fruit at different depths and chopping fruit (simulating tilling), the following treatments were compared: (1) control: fruit on soil surface over window screen (the edges of which were buried), (2) tilling: fruit on soil was repeated chopped and turned into the soil with spade shovels, then covered with screen (edges of screen buried), (3, 4 and 5) consisted of fruit buried $0.15,0.30$ and $.46 \mathrm{~m}$ respectively below soil surface (soil was covered with screen, edges of screen were buried in the soil). Zucchini (infested with melon fly larvae) were collected from a farm and divided into 5 approximately equal quantities. Fruit mass $(\mathrm{Kg})$ and number per treatment were (1) 9.1 and 34, (2) 8.1 and 25, (3) 9.5 and 31, (4) 9.5_and 37, (5) 9.1 and 35. The window screen used to cover the treatments was $1.2 \mathrm{~m}^{2}$ and approximately $20 \mathrm{~cm}$ at the edges of the screen were buried around the treatment area. After the larvae to pupate and emerge as adults, 4 soil bore samples were taken around the edge of the screen where fruit had been placed on the surface of the screen (treatment 1 , see trial 5 for details of the soil 
boring). The distance from the screen to the bore and the distance from the nearest fruit to the inside and outside edge of the bore were recorded. Screens were then removed from each treatment, adult flies captured on the surface under the screen were counted, and three soil bores were taken in each treatment, with one exception. Four bores were taken under the screen for treatment 1 . The total flies recovered in each treatment were compared using binomial confidence intervals. The number of pupae recovered in the soil bores were regressed against depth of the fruit.

\section{RESULTS}

Trial 1, 2 and 3: The data from the first three trials are combined for replication in the analysis. Although there was considerable variation between the trials, the net results were a confirmation of the null hypothesis (Table 1.). Although smashing and treating fruit with pesticide did reduce the total number of emerging flies the, the differences were not significant $(F=0.97, \operatorname{Pr}>F=0.4512)$. Even in the case of the Phifertex ${ }^{\circledR}$ screen on the floor of the augmentorium, the mean number of emerging flies prevented from flying into the protein bait traps (219.7 \pm 925.2) did not differ significantly from the control $(\mathrm{P}>|\mathrm{t}|=0.1308)$. Analyzing the results based on number of flies trapped per $\mathrm{Kg}$ of fruit and per number of fruit did not allow greater discrimination between treatments (Table 1). If we consider the probability that any given larvae would survive in each treatment, the difference between the control and the Phifertex ${ }^{\circledR}$ treatment is apparent. In trial 2, the binomial confidence interval $(\propto=0.05)$ for Phifertex ${ }^{\circledR}$ was $314 \pm 123.3$, and in trial 3 was $239 \pm$ 62.2; the controls were 4825 and 2433 respectively. However, we are more concerned about the cumulative survival and the impact that has on the increase in fly population. The survival rate of 6.5 and $9.8 \%$ over Phifertex ${ }^{\circledR}$ might be considered an acceptable reduction in fly eclosion. The fruit smashing and malathion treatments did not sufficiently impact the emerging fly population to warrant reliance on either of these treatments.

Table 1. The mean numbers of flies caught in protein bait traps over the 4 fruit treatments in the first 3 trials. Means and standard errors followed by the same letter are not significantly different at $\alpha=0.05$ by LSmeans and Tukey tests.

\begin{tabular}{|c|c|c|c|c|c|c|}
\hline \multirow[t]{2}{*}{ Treatments } & \multicolumn{6}{|c|}{ Mean number of flies recovered in protein bait traps over infested fruit } \\
\hline & $\begin{array}{l}\text { Flies } \\
\text { caught }\end{array}$ & S.E.M. & $\begin{array}{c}\text { Flies / kg } \\
\text { of fruit }\end{array}$ & S.E.M. & Flies /fruit & S.E.M. \\
\hline 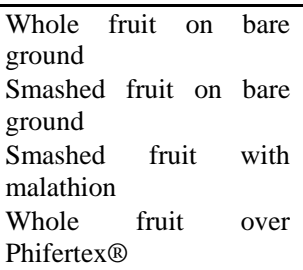 & $\begin{array}{r}2421.7 \\
1383.3 \\
1026.3 \\
219.7\end{array}$ & $\begin{array}{l} \pm 1390.8 \mathrm{a} \\
\pm 982.3 \mathrm{a} \\
\pm 720.8 \mathrm{a} \\
\pm \quad 60.8 \mathrm{a}\end{array}$ & $\begin{array}{l}69.8 \\
39.5\end{array}$ & $\begin{array}{l} \pm 42.0 \mathrm{a} \\
\pm 29.1 \mathrm{a} \\
\pm 20.9 \mathrm{a}\end{array}$ & 11.4 & $\begin{array}{l} \pm 12.1 \mathrm{a} \\
\pm 8.5 \mathrm{a} \\
\pm 7.1 \mathrm{a} \\
\pm 0.5 \mathrm{a}\end{array}$ \\
\hline
\end{tabular}

Trial 4: This trial was a test of the traditional fly control methods. It was not repeated because the results confirmed the results of trials 1 through 3 . The total emergence and binomial confidence intervals are presented in Table 2. Note that the binomial CI is a measure of the likelihood that individual larvae would survive to adulthood. The issue of whether fly emergence in our trials were comparable to mean fruit infestation in the growers fields can be addressed with data provided by the Area Wide Fruit fly IPM project. Between Jul 10, 2001 and Dec. 23. 2002, the average emergence of melon fly larvae per Kg. of green zucchini was $49.6 \pm 8.7(n=298)$ and from yellow zucchini was $43.1 \pm 9.3$ (n 101). This was during the period when efforts to reduce overall fruit fly infestation were being implemented. In our trials, which ended on Jul. 19, 2001, overall average emergence of control treatments was $79.8 \pm 23.6$ melon fly larvae/ Kg. As expected, a sample of c.a. $30 \mathrm{Kg}$ of fruit had a probability of being highly infested, at the time of the trials.

Even repeated pesticide applications on either whole or smashed fruit did not sufficiently or reliably reduce the emergence of adult flies. Whereas emergence of sprayed whole fruit was 2.8 times lower than that of unsprayed whole fruit, emergence of sprayed smashed fruit was 3.3 times greater than that of unsprayed smashed fruit. The important fact is that even a 2.8 fold reduction in eclosion induced by smashing and a 2.7 fold reduction induced by pesticide applications to whole fruit is not adequate for fruit fly control with $>400$ flies eclosing, even in the most effective treatments. 
Table 2. The proportion of flies recovered in protein bait traps over the 4 fruit fly treatments in the fourth trial. The binomial $95 \%$ confidence intervals are calculated by this formula: $\pi=\mathrm{P} \pm 1.96 \sqrt{ }\{[\mathrm{P}(1-\mathrm{P})] /(\mathrm{n}-1)\}$, where $\mathrm{n}$ is assumed to be the number of flies emerging in the control treatment (e.g. 1223 total flies).

* the absolute value of $\{[\mathrm{P}(1-\mathrm{P})] /(\mathrm{n}-1)\}$ was used to calculate the CI for the fly catch that exceeding the control treatment’s catch.

\begin{tabular}{l|cccccc}
\hline Treatments & \multicolumn{6}{|l}{ Mean number of flies recovered in protein bait traps over infested fruit } \\
\cline { 2 - 7 } & $\begin{array}{l}\text { Flies } \\
\text { caught }\end{array}$ & $\begin{array}{l}\text { Binomial } \\
\text { confidence } \\
\text { interval }\end{array}$ & $\begin{array}{l}\text { Flies / kg } \\
\text { of fruit }\end{array}$ & $\begin{array}{l}\text { Binomial } \\
\text { confidence } \\
\text { interval }\end{array}$ & Flies /fruit & $\begin{array}{l}\text { Binomial } \\
\text { confidence } \\
\text { interval }\end{array}$ \\
\hline $\begin{array}{l}\text { Whole fruit on bare } \\
\text { ground }\end{array}$ & 1223 & \pm na & 33.2 & \pm na & 10.8 & \pm na \\
$\begin{array}{l}\text { Whole fruit with } \\
\text { malathion (x 3) }\end{array}$ & 456 & \pm 33.16 & 12.1 & \pm 5.52 & 4.5 & \pm 3.33 \\
$\begin{array}{l}\text { Smashed fruit on } \\
\text { bare ground }\end{array}$ & 434 & \pm 32.81 & 11.5 & \pm 5.45 & 4.3 & \pm 3.31 \\
$\begin{array}{l}\text { Smashed fruit with } \\
\text { malathion (x 3) }\end{array}$ & 1436 & $\pm 31.25^{*}$ & 37.6 & $\pm 4.44^{*}$ & 13.8 & $\pm 4.02^{*}$ \\
\hline
\end{tabular}

However, to further clarify the ineffectiveness of the traditional treatments, we analyzed the data in a different grouping. In the first three trials, some treatments are the same as in trial 4 (i. e. whole fruit and smashed fruit). Because the repeated application of _pesticide had no incremental effect on mortality, we decided to combine the smashed fruit + malathion treatments. Only the treatment, whole fruit with malathion, is not replicated. Eliminating trial 1 because of the low overall emergence in that trial, we combined trial 2, 3 and 4 in an analysis of variance. We weighted the analysis by the number and weight of fruit per trial. We found the number of fruit to have the more significant effect. In this analysis, as in the comparison of trials 1 through 3 , the overall model was not significant $(\mathrm{F}=1.28, \mathrm{Pr}>\mathrm{F}=0.3615)$ (Table 3). In least squares means comparison only the treatment, whole fruit over Phifertex ${ }^{\circledR}(274.8 \pm$ 941.9), allowed fewer flies $(\mathrm{P}>|\mathrm{t}|=0.0751)$ to escape to the dome trap than the control (whole fruit on bare ground, $2808.3 \pm 764.4$ ). No other treatment's mean differed from the control. Although there were 1.5 to 2 fold reductions in trapped flies (1513.7 \pm 775.9 for smashed fruit, and $1398.7 \pm 796.9$ with the addition of malathion), neither is an effective treatment for interdicting fly eclosion.

Table 3. The mean numbers of flies caught in protein bait traps over the 5 fruit treatments in the $2^{\text {nd }}, 3^{\text {rd }} \& 4^{\text {th }}$ trials. Means and standard errors followed by the same letter are not significantly different at $\alpha=0.05$ by LSmeans and Tukey tests (SAS, 1988).

* $\mathrm{P}>|\mathrm{t}|=0.0751$ that whole fruit on ground differs from whole fruit over Phifertex.

\begin{tabular}{l|lllllll}
\hline Treatments & \multicolumn{6}{|c}{ Mean number of flies recovered in protein bait traps } & over infested fruit \\
\cline { 2 - 7 } & $\begin{array}{l}\text { Flies } \\
\text { caught }\end{array}$ & S.E.M. & $\begin{array}{l}\text { Flies/Kkg } \\
\text { of fruit }\end{array}$ & S.E.M. & Flies /fruit & S.E.M. \\
$\begin{array}{c}\text { Whole fruit on bare } \\
\text { ground }\end{array}$ & 2808.3 & $\pm 764.4 \mathrm{a}$ & 79.8 & $\pm 23.6 \mathrm{a}$ & 22.6 & $\pm 6.9 \mathrm{a}$ \\
$\begin{array}{c}\text { Smashed fruit on } \\
\text { bare ground }\end{array}$ & 1513.7 & $\pm 775.9 \mathrm{a}$ & 42.8 & $\pm 24.0 \mathrm{a}$ & 12.5 & $\pm 7.0 \mathrm{a}$ \\
$\begin{array}{c}\text { Smashed fruit and } \\
\text { malathion (1-3) }\end{array}$ & 1398.7 & $\pm 769.9 \mathrm{a}$ & 38.0 & $\pm 24.6 \mathrm{a}$ & 12.9 & $\pm 7.3 \mathrm{a}$ \\
$\begin{array}{c}\text { Whole fruit \& } \\
\text { malathion (1-3) }\end{array}$ & 456.0 & $\pm 1465.7 \mathrm{a}$ & 12.1 & $\pm 45.3 \mathrm{a}$ & 4.5 & $\pm 13.3 \mathrm{a}$ \\
$\begin{array}{c}\text { Whole fruit over } \\
\text { Phifertex® }\end{array}$ & 274.8 & $\pm 941.9 \mathrm{a} *$ & 7.5 & $\pm 29.1 \mathrm{a}$ & 2.2 & $\pm 8.6 \mathrm{a}$ \\
\hline
\end{tabular}

Trial 5: Eclosion of flies in this trial was affected by both the configuration of the fruit on the screen $(\mathrm{F}=$ 194.45, P $>\mathrm{F}<0.001$, where mean flies in traps for piled and single fruit were 440.5 and 271.9, respectively) and by the type of screen used ( $\mathrm{F}=$ 66.98, $\mathrm{P}>\mathrm{F}<0.001$, where mean flies in traps for Phifertex ${ }^{\circledR}$ and window screen were 498.7 and 230.19 respectively). There were no significant differences in the number of adult flies recovered below the screens, nor were there differences in the number of puparia recovered in the 3 bore holes taken under each screen. Regarding the puparia, 3 samples may have been inadequate to separate treatment effects. Regarding the adults, there was some visible evidence of ant predation of the adult fly carcasses under the screens, because ants could penetrate both types of screen. The logistically mandated design did not allow for separation of each combination of treatments in an analysis of variance, but the total catch was compared by binomial confidence intervals (Fig. 3). This indicates that each treatment combination makes a significant difference in the probability of larval survival. 
We were able to use the soil-bore sample data to model the distribution of the puparia under and beyond the screen. We first applied a linear model to the number of puparia recovered at distances from the screen (Fig. 4). The trend of this model indicated, with a high likelihood $\left(\mathrm{r}^{2}=0.2727, \mathrm{~F}=49.12, \mathrm{P}>\mathrm{F}<\right.$ $0.001)$, that we could predict the distance $(70 \mathrm{~cm})$ that screen would need to extend beyond the fruit (or fruit pile) to intercept all of the larvae that moved off the fruit. This model is not the best fit to the data.
The better fit of a Gaussian 3 parameter model approximates the normal distribution with mean pupating distance of $13.88 \pm 1.76 \mathrm{~cm}$, median of 16 $\mathrm{cm}$, skewness of 0.063 and $95 \%$ confidence limits of 10.4 to $17.4 \mathrm{~cm}$. (Fig. 5). We concluded that larvae that are capable of propelling themselves off the fruit pile are distributed nearly randomly within a distance of $70 \mathrm{~cm}$. An ANOVA did not indicate any significant difference in the pupation distance due to the screen or fruit configuration.

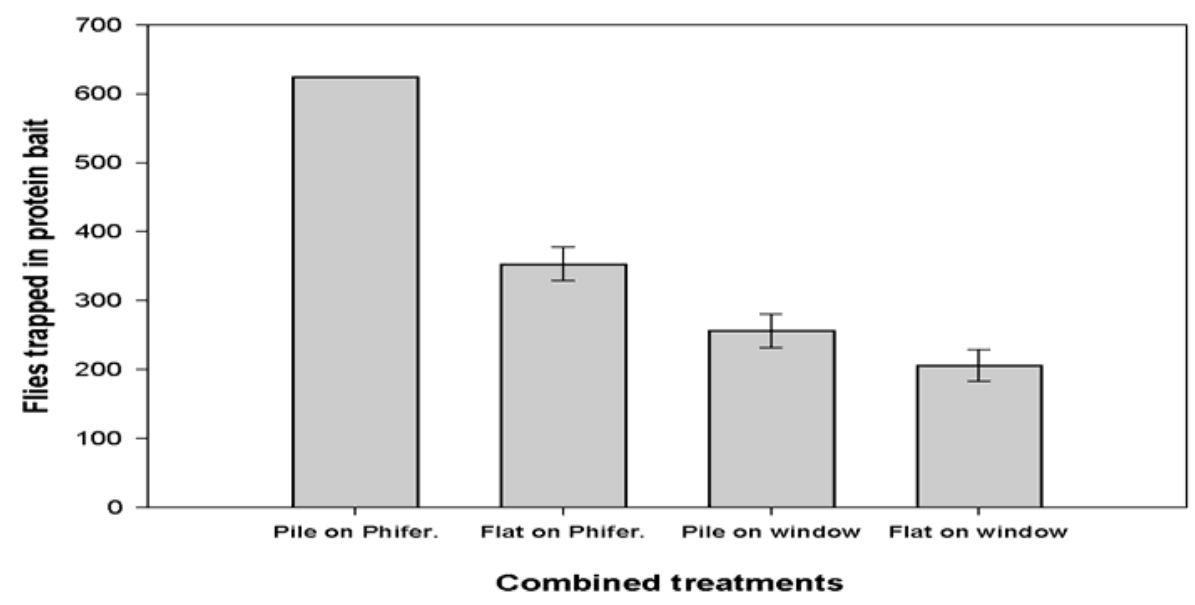

Fig 3. The number of flies trapped over the combined treatments indicates that both the type of screen and the configuration of the fruit affected the number of flies that moved off the screen to pupate. Binomial confidence intervals are computed using the maximum flies recovered in one treatment as the sample size (n).

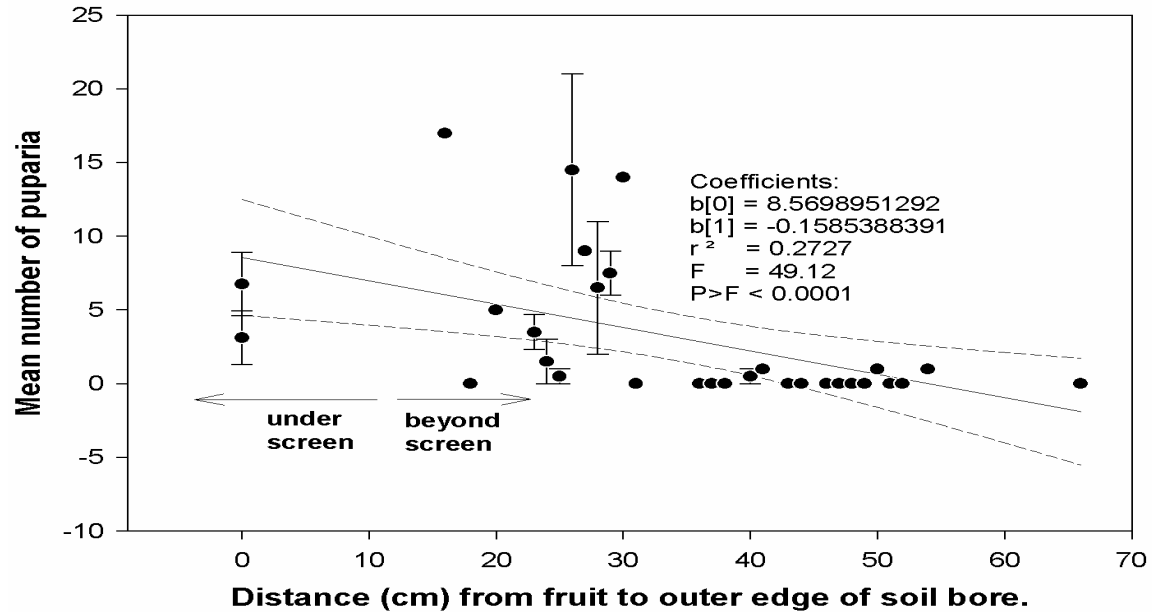

Fig 4. A linear regression of the distance at which flies pupated under and beyond the ground screens indicates that all of the pupae were located within $70 \mathrm{~cm}$ from the fruit. The regression is represented by the $95 \%$ confidence band (-----) and line ( - - $)$. 


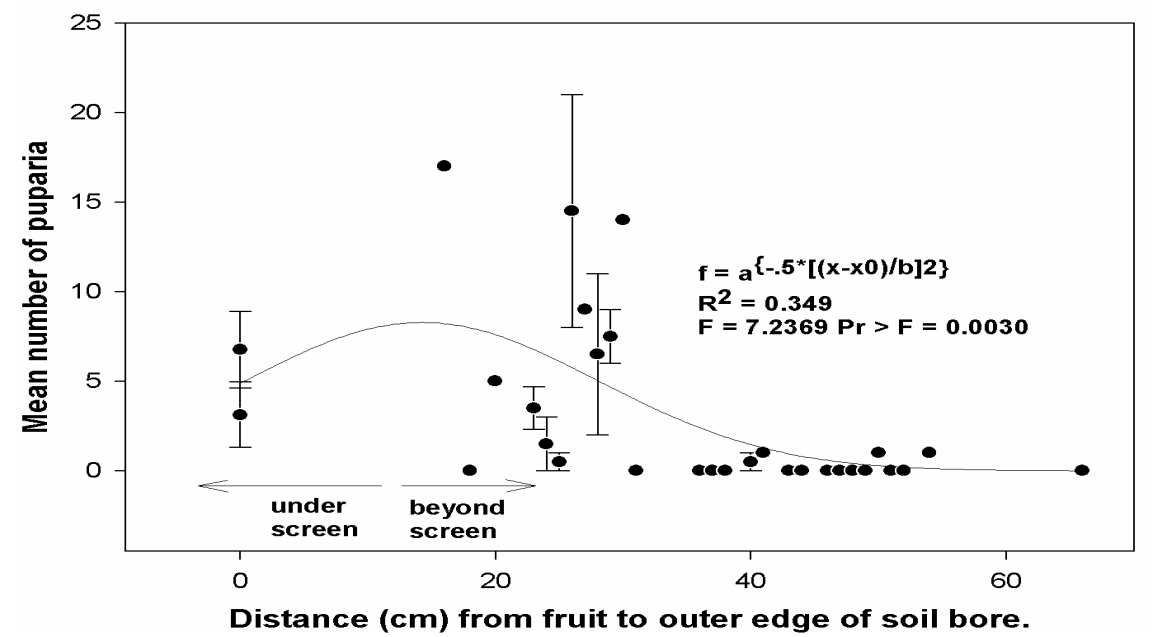

Fig 5. A Gaussian model ( - ) of the distance of pupation indicates that the larvae propel themselves off the screen with a nearlv normal distribution (skewness $=0.063$ ).

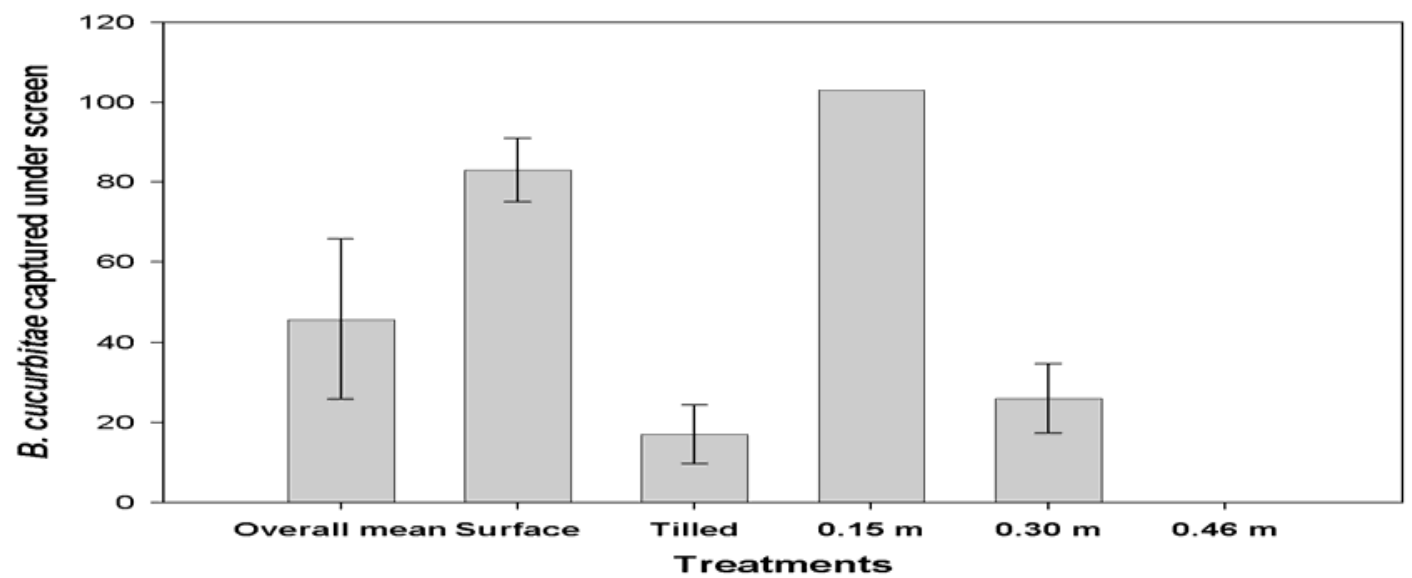

Fig 6. Comparing the number of adult flies recovered at the surface of the ground under screen, burying under $0.46 \mathrm{~m}$ and tilling greatly reduced the number of escaping flies. The surface treatment showed that fewer flies penetrated window screen to pupate than escaped from fruit buried $0.15 \mathrm{~m}$. The latter treatment was used as sample size (n) to compute the binomial confidence intervals.

Trial 6: Because of the design of this trial, treatments could not be compared with analysis of variance for all dependent variables. The adult flies recovered in the screen traps could be compared with binomial CI (Fig. 6). The mean for all treatments was $45.80 \pm$ 19.97. From fruit at the surface, $83 \pm 7.91$ flies were recovered under the screen. Tilling the fruit reduced the number of emerging flies to $17.00 \pm 7.42$ flies. The highest number of flies (103 \pm na) were recovered at the surface of the ground over fruit that was buried $0.15 \mathrm{~m}$. Even when the fruit was buried $0.30 \mathrm{~m}, 26 \pm 8.68$ flies were able to burrow to the soil surface. No flies were recovered over fruit buried $0.46 \mathrm{~m}$. These differences were also reflected in the soil bores (Fig. 7). Significantly fewer puparia were recovered in the tilled sample $(2.30 \pm 2.30)$ compared to the fruit placed on the surface of the soil (4.05 \pm 1.83). Only 1 puparia was recovered in the boreholes made outside screen in the surface treatment, indicating that there was sufficient border to minimize pupation off the screen. Of the 3 buried fruit treatments, puparia were only recovered where fruit were buried $0.15 \mathrm{~cm}(1.3 \pm 0.67)$. This is deeper than pupation would normally occur (Jackson et al. 1998), so we speculate that the larvae probably burrowed toward the soil surface before pupating within the $8 \mathrm{~cm}$ depth of the soil bore. No pupae were recovered from the samples buried 0.30 and $0.46 \mathrm{~m}$. The adult flies that did escape to the surface from a depth of $0.30 \mathrm{~cm}$ might have pupated close enough to the surface to make escape possible. However, it is more probable that these larvae pupated near the buried fruit, but were able to escape through crevices created when the soil collapsed on the desiccating fruit. 


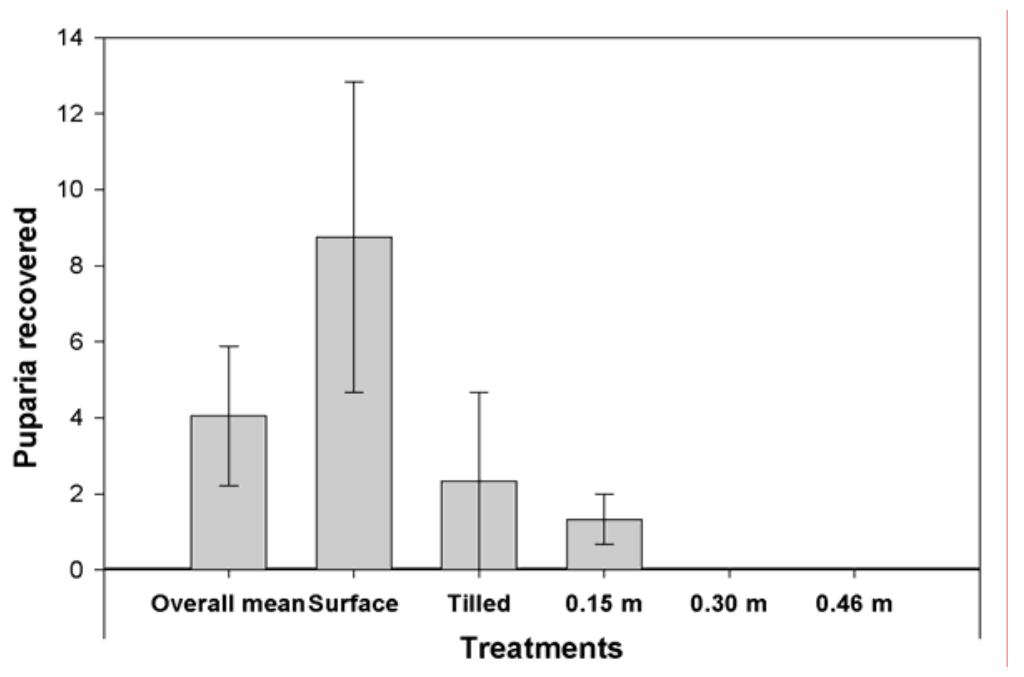

Fig 7. Puparia recovered in 3 soil bores (each ca. $603.4 \mathrm{~cm}^{3}$ ) per treatment, indicated that progressively fewer larvae pupated within $8 \mathrm{~cm}$ from the surface with tilling or depth of burying. Four soil bores under the screen in the surface treatment yielded the greatest mean number of puparia.

\section{DISCUSSION}

The results of the first 4 trials give ample evidence that fruit smashing and pesticide treatments, or both, cannot kill enough of the fly larvae to stop the everexpanding cycle of melon fly population increase. Proponents of pesticide might argue that the timing was not right, or the pesticide dosage was not adequate. That is abundantly clear, but that is also a principle reason why fruit flies have continued as an expensive pest in Hawaiian crops for years. Particularly the results of trial 4 show how unpredictable larval survival can be. The focal point should be the inadequate control of fly emergence even in the pesticide treatment with the lowest emergence ( $>434 \pm 32.81$ survivors). The objective is not to find the optimum pesticide application schedule. Over the last 40 years, that approach has not given adequate control of melon fly in Hawaiian crops. Thus weekly applications of dimethoate and dibrom still allow 15 to $30 \%$ or higher fruit infestation (Chou et. al. 2002).

We do not have an explanation as to why the smashed fruit with three treatments of malathion yielded such high numbers of live adults (Trial 4). Even if the random sample had an unusually high number of larvae, it is clear that the malathion did not affect the larvae. One possible explanation is that the smashing process may have induced the larvae to burrow into the soil beyond the reach of the pesticide. Larvae in the whole fruit might have taken longer to emerge from the fruit, and therefore been more likely to encounter malathion from one of the three spray treatments. In any case, over 400 survivors emerged in that treatment as well.

As pesticide usage increased to weekly or more frequent "calendar" sprays (Hollingworth et al. 1994, Purcell et al. 1995), the production of many fruit-fly susceptible crops declined in Hawaii (State of Hawaii Agriculture Statistics). Purcell et al. (1994) demonstrated that 3 pesticides commonly used against fruit flies were $>100$ times more toxic to the parasitoid wasps that were introduced to Hawaii to reduce the fruit fly populations. Purcell speculated that because Psyttalia fletcheri was the least susceptible to the pesticides, and is the only one of the introduced wasps that can reproduce in melon fly, it might have developed some resistance due to the constant exposure to pesticide on fruiting vegetable crops.

Although tephritid fruit flies have not been shown to develop pesticide resistance, aphids (Hollingsworth et al., 1994 and 1997), whiteflies (Omer et al., 1993) and leaf miners (Purcell et al., 1995) have developed resistance under constant foliar pesticide pressure in Hawaii. Even parasitoid-host complexes have shown resistance to the pesticides commonly used against foliar feeders such as leaf miners (Rathman et al. 1995, Spollen et al. 1995). Foliar applications to crops to control fruit flies only added to pesticide resistance and increase the costs of production. Therefore, the objective should be to determine if there is a more reliable way to stop the reproductive cycle without resorting to toxic chemicals. It is clear from the first 3 trials and the $5^{\text {th }}$ trial that ground 
screen has good potential for controlling emergence of pupated larvae. In the former trials the larvae were forced to pupate on or below the screen. The average emergence of flies over Phifertex ${ }^{\circledR}$ in these trials indicates that $9.7 \%$ of the flies can pupate in the fruit on top of the screen, even when they have no other choice than to burrow through screen. Nevertheless, that means $90.3 \%$ of the larvae penetrated the screen to pupate in the soil.

In trial 5, where the larvae could pupate on or off the screen, they showed a random pattern and range of dispersal away from the fruit. This information can be used to design a strategy for deploying ground screen as a barrier against adult fly eclosion. Whether cull fruit is piled over a screened area of ground, or placed on strips of screen deployed throughout the crop, screen can be used to control larvae. We propose that a boarder of $0.7 \mathrm{~m}$ from the fruit to the bare ground is required to insure that most larvae will pupate below the screen. Although common window screen appeared to be more effective than Phifertex ${ }^{\circledR}$, we were comparing a gray window screen to a yellow Phifertex ${ }^{\circledR}$. Also, we have demonstrated that Phifertex ${ }^{\circledR}$ has an aperture that will allow fruit fly parasitoids to escape into the crop environment (Klungness, unpublished data). The weave of window screen is too tight to allow important braconid parasitoids to pass. Therefore, further work is needed to compare screens more similar in color, to see if one of the darker colors of Phifertex ${ }^{\circledR}$ would perform as well as window screen. Nevertheless, this ground-screen technique was more effective than pesticide in our trials, and has a potentially more limited environmental impact that pesticide. It also affords opportunities to recycle the organic waste.

Considering the results for the first five trials, the reader will have a natural tendency to consider the augmentorium as being the experimental chamber, and look only at the differences between treatments within the chambers. Therefore we must point out that the augmentorium sequestered all adult flies that emerged from the infested fruit, (unpublished laboratory and field performance data of Klungness). All other methods, with the exception of burying cull fruit $0.47 \mathrm{~m}$ deep, let a portion of the adult flies escape. With a net reproductive rate of 317.5 for $B$. cucurbitae and 418.5 for B. dorsalis (Vargas et al. 1984), each eclosing adult female threatens a resurgence of the population. Although this study was conducted exclusively with melon fly, the same sanitation techniques are applicable to the other tephritids found in Hawaii. It behooves the grower to consider what is the real cost of not interdicting the immature stages of the fruit fly with one of these more efficient systems of sanitation.

Acknowledgments: We acknowledge the support of the USDA, Area Wide Program, I. P. M. of Fruit Flies in Hawaii, for financial support, and R. Messing (Univ. of Hawaii) and D. Ullman (Univ. of Calif., Davis), for initial support of the early development of the augmentorium through the Low Input Sustainable Agric. Grant program. We thank the growers (R. Kametani, V. Griengo, B. Yamamoto, R. Koga and G. Shishido), Univ. of Hawaii Cooperative Extension staff (Robin Shimabuku, David Ota), and the members of the Area Wide Project staff: T. Kawahara, C. Chan, D. Ota and Ming Yi Chou for their assistance. We thank B. Dowell, T. Haller, A. Alyokhin, G. McQuat for critical reviews of the manuscript.

\section{REFERENCES}

Allwood A.(2000) Regional approaches to the management of fruit flies in the Pacific, pp. 439448, in Area Wide Control of Fruit Flies and Other Insect Pests. Keng-Hong Tan (ed.), Sinaran Bros., Sdn. Bhd. , Penang, Malaysia.

Chou M. Y., Mau R. F. L., Pandey R. R. (2002) Encouraging results from the fruit fly suppression program in Oahu, in HAW-FLYPM Newsletter, Sugano J. and Hiraki C. (ed.), Coop. Ext. Serv., Col. of Trop. Agric. \& Human Resources, Univ. of Hawaii, Aug. 1.

Dowell R. V., Siddiqui I. A., Meyer F. and Spoungy E. L. (2000) Mediterranean fruit fly preventative release programme in southern California, pp. 369-375, in Area Wide Control of Fruit Flies and Other Insect Pests. Keng-Hong Tan (ed.), Sinaran Bros., Sdn. Bhd. , Penang, Malaysia.

Hollingsworth R. G., Tobashnik B. E., Ullman D. E., Johnson M. W. and Messing R. H. (1994) Resistance of Aphid gossypii (Homoptera: Aphididae) to insecticides in Hawaii: special patterns and relations in insecticide use. J. Econ. Entomol. 87:2 293-300.

Hollingsworth R. G., Tobashnik B. E., Johnson M. W., Messing R. H. and Ullman D. E. (1997) Relationship between susceptibility to insecticides and fecundity across populations of cotton aphid (Homoptera: Aphididae) J. Econ. Entomol. 90:1 55-58.

Jackson C. G., Long J. P. and Klungness L. M. (1998) Depth of pupation in four species of fruit flies (Diptera: Tephritidae) in sand with and 
without moisture. J. Econ. Entomol. 91:1 138142.

Klungness L. M. (2001) Program update, in HAWFLYPM Newsletter, J. Sugano and C. Hiraki(ed.), Coop. Ext. Serv., Col. of Trop. Agric. \& Human Resources, Univ. of Hawaii, Aug. 28, 1. on world wide web at http://www.fruitfly.hawaii.edu/

Omer A. D., Johnson M. W., Tabashnik B. E., Costa H. S. and Ullman D. E. (1993) Sweetpotato whitefly resistance to insecticides in Hawaii: intra-island variation is related to insecticide use. Entomol. exp. appl. 67: 173-182.

Pandey R. R. (2004) Plan your sudex borders for melon fly control, in HAW-FLYPM Newsletter, C. Hiraki (ed.), Coop. Ext. Serv., Col. of Trop. Agric. \& Human Resources, Univ. of Hawaii, February 2004. on world wide web at http://www.fruitfly.hawaii.edu/

Purcell M. F., Johnson M. W. and Tabashnik B. E. (1995) Effects of insecticide use on abundance and diversity of tomato pests and associated natural enemies in Hawaii. Proc. Hawaii. Entomol. Soc. 32: 45-59.

Purcell, M. F., Stark J. D., Messing R. H. (1994) Insecticide effects on three tephridid fruit flies and associated braconid parasitoids in Hawaii. J. Econ. Entomol. 87:6, 1455-1462.

Rathman R. J., Johnson M. W., Tabashnik B. E.and Spollen K. M. (1995) Variation in susceptibility to pesticides in the leafminer parasitoid Ganaspidium utilis (Hymenoptera: Eucoilidae). J. Econ. Entomol. 88: 475-479.
SAS User's Guide to Statistics, Version 8, SAS Institute Inc. (1999) Cary. North Carolina, p956.

Seewooruthun S. I., Permalloo S., Gungah B., Soonnoo A. R. and Alleck M. (2000) Eradication of an exotic fruit fly from Mauritius, pp. 389393, in Area Wide Control of Fruit Flies and Other Insect Pests. Keng-Hong Tan (ed.), Sinaran Bros., Sdn. Bhd., Penang, Malaysia.

Spollen K. M., Johnson M. W. \& Tabashnik B. E. (1995) Stability of fenvalerate resistance in the leafminer parasitoid Diglyphus begini (Hymenoptera: Eulophidae). J. Econ. Entomol. 88: 192-197.

Tan, Keng-Hong, (Ed.) (2000) Area Wide Control of Fruit Flies and Other Insect Pests. Sinaran Bros., Sdn. Bhd. , Penang, Malaysia, p782.

van Sauers-Muller, A. (1993) Pilot eradication project for the Carambola fruit fly in Coronie, Surinam, pp. 439-442, in Fruit Flies, Biology and Management. M. Aluja and P. Liedo (Eds.) Spring-Verlag, New York, NY.

Vargas, R. I., Miyashita D. and Nishida T. (1984) Life history and demographics of three laboratory-reared tephritids (Diptera: Tephritidae) Ann. Entomol. Soc. Am., 77, 651656.

Wonnacott, T. H. and Wonnacott R. J. (1977) Introductory Statistics, $3^{\text {rd }}$ Ed., p649. 